\title{
MIGRATION AND THE EXTREME RIGHT IN WESTERN EUROPE
}

\author{
Harry Nedelcu \\ Carleton University \\ Chris Miller \\ Carleton University
}

\begin{abstract}
The relationship between migration and extremist parties has been an overlapping topic in studies of party systems, citizenship, and migration. This body of work has collectively challenged the view that the success of radical right parties in Western Europe is an unavoidable consequence of increased immigration flows. Through a review of four recent studies, this article will attempt to unpack recent scholarly literature with the aim of investigating the salience of the causal link between immigration and the success of radical right parties. The four works studied arrive at separate conclusions due to their different conceptual understandings of agency in party systems as well as their assumptions about the nature of political mobilization. While three feature the mobilization of immigration as an electoral issue as being an important factor for the success of far right parties, one makes the claim that national definitions of citizenship shape both responses to migration within the host state as well as the space available for the radical right.
\end{abstract}




\section{Introduction}

The relationship between migration and manifestations of political and social extremism has been an overlapping topic in studies of party systems, citizenship, and migration. This diverse body of work has collectively challenged the view, particularly prevalent in public spheres, that the success of radical right parties in Western Europe is an unavoidable consequence of immigration or increased immigration. The link between the two has been visited by a number of authors, with a number of factors proffered to explain how social discontent is processed into a unique form of politics sensitive and hostile to the presence of outsider groups. Among such factors are forms of party organization, institutional constraints, challenges to identity, and conceptions of citizenship. In recognizing these contributions, it is worth asking how the link between patterns of immigration and the success of far-right parties has been conceptualized. Four recent studies have provided a fertile basis for exploring this question: Cas Mudde's Populist Radical Right Parties in Europe, Michelle Hale Williams' The Impact of Radical Right-Wing Parties in West European Democracies, Terri Givens' Voting Radical Right in Western Europe and Contested Citizenship: Immigration and Cultural Diversity in Europe by Ruud Koopmans, Paul Statham, Marco Giugni, and Florence Passy.

By no means is this review aimed at unravelling general theories of far right parties in Europe, a party family that commands a significant amount of attention in comparative research. ${ }^{\text {i }}$ Consequently, the intent is not to define the radical right or to determine the motivations of their electoral bases. Studies particularly and exclusively focused on the far right have contributed to such debates for over two decades and are still active. Instead, this review will unpack recent scholarly literature (with an eye to Western Europe) with the aim of understanding the debate surrounding the question of radical right parties and their relationship to immigration. We conclude that the four works arrive at different conclusions due to their approaches as well as assumptions. While the first three feature the mobilization of immigration as an electoral issue as being an important factor for the success of far right parties, Koopmans et al. claim that national definitions of citizenship shape both responses to migration within the host state as well as the space available for the radical right.

\section{Why Now?}

Throughout and beyond the 1990s, a surge in radical right politics in Western Europe captured the attention of observers both inside and outside the EU, peaking with Jean-Marie Le Pen's surprise secondplace showing in the 2002 French presidential election. Givens and Williams note that such a victory would have seemed unimaginable only a decade earlier. But what is the larger significance to party systems in these developments? Both scholars and political figures have "long alluded to a threat potential from radical right-wing parties” (Williams 2006, 12), but evaluation of this rhetoric is an ongoing debate that highlights different assumptions about the agency of political parties. Conventional models of party systems which stress the role of broad, brokerage parties suggest that these new far right parties are marginal, and that concern regarding the role they may play in substantive policy-making is likely overstated. Radical right parties, it is noted, are often small and lacking in legislative representation and at most operate as junior partners in coalition governments (Williams 2006, 3). Yet this is a limited view of party systems, and indeed, of politics in general, and undersells the impact that such parties have throughout Western Europe.

Agenda-change is available to parties outside government, with consequences that have manifested themselves in the priorities of Western European states. The debate thus has implications beyond the link between migration and radical right parties. It is, as Williams states, "about understanding political change in advanced capitalist, Western democracies” (Williams 2006, 3). It is about recognizing that marginal politics do matter, but at the same time recognizing that they require different understandings than do mass politics. 


\section{Migration and the Radical Right}

Mudde's Populist Radical Right Parties in Europe represents a useful starting point for exploring recent scholarly insights into the relationship between migration and radical right parties. Although Mudde's work is too extensive to be summarized here, his conclusions on the secondary role of economic factors in the immigrant-radical right relationship as well as his typological model for the success of radical right parties are crucial to this discussion.

Central to Mudde's understanding is his observation that populist radical right parties are not, as he terms it, "passive consequences of macro-level socioeconomic indicators". Instead, he argues that such parties also "supply" their own relevance to the extent that they "actively shape part of their own destiny" (Mudde 2007, 293). Mudde's emphasis on the role of the party does not necessarily neglect the "demand" dimension of such parties. He does note, in fact, that social changes brought about through forces of modernization and globalization have provided a context for xenophobia and political resentment (Mudde 2007, 230). Rather, he stresses the useful observation that this environment is not the only explanatory factor underlying the growth of radical right parties. Their success is as much an account of the ability of these parties to effectively link with voters on issues of identity.

Consequently, Mudde finds that nativism (the congruence between a state's population and a "native" group), authoritarianism and populism are reoccurring features of such parties and in fact constitute what he terms the "three pillars" of the populist radical right (Mudde 2007, 294). This classification operates rather broadly and as a result Mudde's populist radical-right sub-family includes a vast array of members such as the French National Front, the Freedom Party, Flemish Interest, Germany's Republican Party and the Danish People's Party, as well as Eastern European far-right parties such as the Greater Romania Party, Croatia's Democratic Movement, and Latvia's National Independence Movement. However, for Mudde, these parties, despite their differences, are similar in their ability to capture the discontent related to the three core features of their ideology (Mudde 2007, 298).

One of the implications of this argument is that it challenges a well-established assumption about the central role of socioeconomic changes in party systems. Mudde considers the economy as a secondary issue for the radical right, arguing that the three mentioned components of their agenda are the ones which truly stand at the centre of party ideology (Mudde 2007, 137). If ideological implications about the economy matter at all, for Mudde, it is because they stem from the 'three pillars', not the other way around. He argues that populist radical right parties garner support regardless of their pro-market or welfare-chauvinist messages. This conclusion challenges the extent to which earlier studies link the radical right phenomenon to socioeconomic developments and therefore complicates the radicalright/migration picture.

However, more importantly for the purpose of this review, Mudde’s first pillar, nativism, and to a certain degree his third pillar, populism, reveal significant features about the relationship between the radical right and migrants. Through his emphasis on 'nativism', Mudde stresses the importance of local ethnic identities and implicitly the ability of the far right to tap into them as a result of competing identities. In summarizing the existing literature, he notes that the main reason for the support of populist radical right parties is "a nativist position on the immigration issue" (Mudde 2007, 220). It is this previously established conclusion which Mudde does not challenge in his examination of the nativist pillar.

Nonetheless, for Mudde, the immigrant is just one type of enemy that comes to the fore out of the us-them, good-bad, inside-outside, and friend-enemy dichotomies which nativism implies. Therefore, the image of the immigrant as an outsider is complemented by additional "others". As nativism is largely about the politics of identity in terms of the nation and the state, Mudde classifies these others in relation to their position within the latter two. He distinguishes between enemies outside the state and outside the nation, outside the state and within the nation, within the state and within the nation and finally, within the state and outside the nation. Only the final category encompasses immigrant communities.

The first group includes foreign powers as well as international organizations such as the European Union and the United Nations. Enemies outside the state and within the nation include 
countrymen who have moved abroad, artists, intellectuals and politicians who have emigrated and who are accused of corruption, leftism and treason (against their native country). Enemies within the state and within the nation are the economic, cultural and political elites. The national elites are characterized both in nativist and populist terms as traitors to the nation and as corrupt elements. This is observed both in the East through examples such as Bulgaria's Ataka, Greater Romania Party or Hungary's MIEP but also in some cases from Western Europe such as Germany's Republicans who blame the mainstream political elite for 're-educating' the native population with the aim of making it passive and self-hating (Mudde 2007, 66).

The media as well as the cultural elite are also amalgamated under the 'traitor' category for aiding and abetting the establishment. More importantly however, another dimension of the 'treachery' of this broad coalition of elites is linked to the issue of immigration as it is these elites which are deemed the true culprits of mass immigration. Immigration is therefore seen as a conspiracy of the aforementioned groups who want to increase their support base and pool of cheap labour at the expense of the nation. Mudde names Italy's Northern League and Austria's Freedom Party among those parties whose programs or party member speeches made references to this aspect. The examples of Greater Romania and Bulgaria's Ataka, similarly demonstrate that the role of the immigrant is replaced by the 'Roma' or the 'Turk' in the East where mass immigration has not yet started.

Finally, Mudde distinguishes the aforementioned 'others' from the enemy within the state and outside the nation. As previously mentioned, it is only this latter 'other' which specifically includes the ethnic minority. In Western Europe this is the immigrant community whereas in Eastern Europe this tends to be larger indigenous ethnic minorities. Mudde identifies the German Republicans, Belgian Flemish Interest, Hungarian MIEP, Slovak SNS, Bulgaria's Ataka and Greater Romania party as parties which highlight this type of 'other'. He argues that the principal accusation is that these minorities, whether immigrants or indigenous, are not loyal to the state they live in and therefore "constitute a fifth column of their kin state" (Mudde 2007, 72). Together with the aforementioned enemies inside the state and inside the nation (the elites) which have allowed for this mass migration or tolerated these fifth columns, ethnic minorities represent an additional element of opposition against the native population.

As his analysis is a party-centric one, Mudde does not explore this further and as previously stated only superficially does he link this to exogenous institutional constraints or demand-side dynamics. Mudde's explanation for the far right lies instead in their ability to occasionally mobilize their voters or those who plan to cast protest votes effectively. The capacity of parties to properly do this is strongly linked to their party organization and leadership. He states that successful parties are characterized either by a moderate ideology, a charismatic leader or well-structured organization (Mudde 2007, 275-276). Charisma can play a crucial role for short-term success, but it cannot help the party remain in such a privileged position for long. Similarly, Mudde points out that the other two factors likewise do not guarantee success if considered in isolation. Mudde argues, therefore, that those parties such as the National Front in France or Flemish Interest in Belgium which are able to combine charisma with administrative competence are the ones which will be most successful in rallying protest voters.

Essentially, by emphasizing the importance of party organization in rallying voters, Mudde claims that the demand side weighs little importance and even when it does, a well organized party with a strong leadership can manipulate it in such a way that success is assured regardless. It is therefore up to the party to successfully employ the image of the immigrant as a useful point against which a certain segment of the population can rally against. However, as the four typologies of enemies illustrate, it is not simply the image of the immigrant which these parties use. Instead, it is the image of the 'other' (resulting from the nativist and populist pillars) as a treacherous and disloyal opponent of both the state and the nation. This image is what ultimately implies a notion of asphyxiation and fosters conspiracy narratives against the native group.

Consequently, it is the ability of radical right parties to tap into popular discontent (towards actors perceived as working against the public interest) using a narrative based on their three ideological pillars through an effective organization and leadership that allows for their success. Simply put, for Mudde, the nativist position on the immigrant issue is indeed a cause for the radical right. In this respect Mudde does 
not challenge the validity of this claim. However, his argument is that this picture is complicated by the fact that the immigrant is a mere facet of a multi-dimensional enemy which includes national elites and international organizations which together aim at assaulting the state and the nation. It is this multifaceted enemy which helps create the image of siege against the native who, subsequently, can be converted into a radical-right voter.

Michelle Hale Williams’ analysis of the radical right in Western Europe uses France, Germany, and Austria as primary case studies. Similar to Mudde, her belief is that the survival and success of such parties depends on their ability to create political opportunities and manoeuvre around existing institutional constraints (Williams 2006, 2). Her institutional analysis is at odds with more traditional explanations that the success of extreme-right politics is dependent on the presence of a socioeconomic climate amenable to such politics. For Williams, party systems matter, electoral systems matter, but most importantly, the ways in which actors are able to interact with these systems matter. All of this ties into a focus on the ability of radical right parties to engage in a broader process of agenda-setting beyond their own internal party dynamics or the political economy of the society in question.

As Williams notes, existing studies presume the "electoral success of radical right-wing parties as the dependent variable and then suggest socioeconomic factors as the causal, independent variables" (Williams 2006, 2). Such socioeconomic factors are typically elaborated as rising immigration rates, unemployment, high population density, and economic stagnation. She largely accepts this environment as a basic explanation for the broader pan-European rise in the radical right but maintains that the influence and success of radical right parties are contingent on other organizational features. What is central to Williams' model is that immigration concerns, as a vehicle for radical right political mobilization, are not endogenous to radical right politics. She suggests that "to some extent the radical right attempts to create the popular interests that provide a basis for party organization” (Williams 2006, 4). Because mainstream parties frequently emphasize issues related to the economy and foreign policy, far right parties must expand into new issue areas. Hence, political opportunity must come "not from reacting to issue concerns but from creating new ones" (Williams 2006, 4). What this suggests is that the presence of immigration as a mobilizing issue is influenced by the context set by the broader political system and that ultimately there is a high degree of agency attributable to the parties of the radical right themselves.

More importantly, her work also raises a far more interesting issue for the future: if more mainstream parties come to embrace immigration issues, as has been apparent with the Labour Party in Britain and the UMP in France, what does this mean for the long-term viability of the radical right? The latter party family has been in many ways a chameleon, adopting particular images to suit its needs at particular times. Would the right continue to pursue anti-immigration politics ad infinitum, constantly moving the agenda of political systems further in that direction? Would it abandon the issue as a central plank, having successfully achieved policy change in that issue area? These are interesting questions for the future. If one extrapolates from Williams model, it may well depend on the particular party in question. Williams establishes a typology that differentiates between fascist legacy parties and the more successful "entrepreneurial” parties who have displayed a willingness to consolidate internal factions and develop coherent platforms in order to maximize electoral votes (Williams 2006, 94). Under this typology, one would presume that legacy parties would be more inflexible towards de-emphasizing immigration, while the latter type could conceivably manoeuvre into other issue areas, at the expense of their immigration politics.

Fundamentally, Williams also challenges the idea that only government-forming parties can wield political power. The common notion that radical right parties are ineffective due to their sizes or statuses as political pariahs is replaced with a more complex interaction in which such parties take a role in formulating policies and political agendas through institutional processes. Hence, the causal link between levels of immigration and immigration backlash is severed, with the institutional frameworks of party politics (both the internal organization of radical right parties and their leaderships, and the national party system as a whole) and legislative/executive systems emerging as intervening variables.

Within this model, the primary enabler of radical right sentiment is the ability for such parties to "select the salient issues to make central in their positions," "to look for events in the status quo that can 
be manipulated," and to "transform these events into threats” (Williams 2006, 4). In this respect, Williams comes close to Mudde in emphasizing the party's internal structure and dynamics as a catalyst for issue formation. Hence, it is only by "connecting real problems to loss of identity and pointing to foreigners as the culprits, the radical right has woven together an elaborate scenario for threat." Among the more successful "real problems" that parties have emphasized are security (particularly post-9/11), the further integration of the European Union (and its resultant effects on issues of identity), and the decline of the welfare state. Moreover, agreeing somewhat with Mudde, Williams admits that the ability of the far right to elaborate such scenarios for threat is not independent from the larger framework of party politics.

Indeed, Williams does find that there have been successes in the form of policy-making. She uses the advocacy of restrictive immigration declarations and the downplaying of the significance of xenophobia, along with the blocking of legislation promoting multiculturalism as the "goals" of radical right parties. What she finds is that actual declines in immigration coincided with a concurrent increase in legislation designed to inhibit immigration and a decrease in legislation designed to combat racism (Williams 2006, 72-73). How has this been accomplished by a set of parties not known for broader electoral success? This is where Williams' unique model comes into play.

Williams elaborates a process whereby far right parties use social forums, such as the media or even the European Parliament, as a means of forcing actual socioeconomic issues through a tenuous "funnel" issue, in this case immigration. Unemployment, crime, insecurity, and poor education are pushed through this lens in order to give salience to the funnel issue by attributing to it a variety of social problems. This form of scapegoating therefore explains how immigration can have such political saliency independent of actual levels of immigration. Ultimately, this leads her to conclude that the immigration issue is created rather than contextual (Williams 2006, 5).

Unlike Williams, who generally accepts unemployment and concentration of immigrants can be useful springboards for the radical right, Terri Givens sets out to empirically test (using the same case countries as Williams) whether such factors are causally related to the success of radical right parties, ultimately finding it to be an untenable link (Givens 2005, 68). Citing prior research by Swank \& Betz, Nonna Mayer, and Pierre Martin, she notes that while asylum rates are associated with support for radical right parties, this does not hold in general for net immigration. Similar findings are noted for unemployment rates. Reasons why this is the case are quite similar to Williams': rather than perceptions of immigration levels mimicking actual levels of immigration, Givens finds that far-right politicians frequently link levels of unemployment to the presence of immigrants, whether such effects are warranted. Hence "if the immigration pressure in a situation of economic crisis provides the general catalyst for the mobilization of the movements of the extreme right, it does not translate directly into a greater mobilization capacity of these movements" (Givens 2005, 78). This is closely in line with Mudde's and Williams' theses that the ability to connect other meaningful issues to immigration is a key variable in the success of radical right parties to implement their policy goals, either directly or indirectly. She also includes, however, a heavy institutional emphasis that is missing from Williams.

Givens makes it clear that she rejects a simplistic focus on economic and political change in Western Europe. While on some theoretical level factors such as unemployment could potentially play a role in stimulating radical right politics (given particular country circumstances), the empirical variations she uncovers means that relying on economic and political conditions alone cannot provide a complete picture of the radical right's rise. Givens embraces prior work that has emphasized the processes of globalization and immigration and their effects on exposed economic sectors. However, immigration is found to be at most an intervening variable, with the propensity for strategic voting (via institutional arrangements encouraging particular coalition structures, factionalism within mainstream parties, and electoral outcomes) being the primary determinant of the successes of radical right politics. This emphasis on institutions is highlighted by her belief that they determine the "rules of the game" and that voters and parties, far from being automatons that reflexively respond to societal conditions, "instead pursue strategies to achieve their goals" (Givens 2005, 153). While this plays into the debate in the sense that successful radical parties are better able to enlarge their political base and clout, it lacks a genesis account 
of radical right politics. Indeed, within her model "it is assumed that a radical right party has already been successful in entering the party system” (Givens 2005, 8).

One interesting finding is the observation that the saliency of each variable is highly contingent upon the given country. Germany's far-right movement is not tied to immigration influx, while Austria and France are slightly sensitive to such changes, though as a variable it is still weaker than originally anticipated by the existing literature (Givens 2005, 85). Why this is so is still unclear. It could be that radical right parties expend more effort in areas affected by unemployment, or that voters in these areas are more responsive to messages of the radical right. If the latter is the case, it would open the door further to Mudde's findings on identity and nativism. What is clear is that this is the point where the interaction between party strategy and socioeconomic factors takes place. It is the point at which common fears or tensions are transformed into social criticism by radical parties and directed at mainstream political establishments.

Overall, Givens offers an interesting picture of how intervening variables interact differently in different states, perhaps giving credence to the historical-sociological method of single-case study analyses typically favoured within studies of far-right politics. Though her account ignores the genesis of such politics, her findings strengthen the idea that the radical right is not dependent on increasing levels of immigration for their electoral successes.

Finally, in their discussion of citizenship, Ruud Koopmans et al. revisit the problem over migrant integration as well as far-right parties in light of institutional constraints. They set out to account for both phenomena by juxtaposing two alternate theories and testing them in five Western European states with the objective of discovering the reasons why differences do exist between different countries. The first theory is based on ethnographic studies and emphasizes cultural, ethnic and political characteristics which might allow both actors (migrants and far-right parties) to highlight such cultural differences. The second lies in institutional and discursive opportunities provided by national citizenship and integration politics (Koopmans 2005, 108-109). Admittedly, there is an implicit weakness in this study as it alludes to a superiority of one over the other without allowing for the possibility that perhaps both are accountable.

Nevertheless, Koopmans et al. stand out from the other three works discussed as they challenge already established assumptions about the causal relationship between voter preferences (in large part due to societal changes such as mass immigration) and radical right parties. For this reason, the contributions by Koopmans et al. are even more significant as having been published in 2005 and thus earlier than the other works which have nonetheless accepted in some form or another some sort of causal relationship between the two. Therefore, albeit being five years old, their study is still quite relevant in this discussion of recent literature on the subject.

In their five case studies, Netherlands, Great Britain, France, Germany and Switzerland, Koopmans et al. conclude that there is little evidence for cultural explanations in relation to migrants exhibiting strong homeland orientation or homeland-directed activism. Instead, they argue that strong migrant transnational orientation (and implicitly lack of integration within the host nation) is a result of "traditional, exclusionary citizenship regimes that put up high barriers to migrants' access to the political community" (Koopmans 2005, 142-143). This is evident from differences across the five states. While in Switzerland and Germany most migrants do not have voting rights and cannot access the policy process, in France cultural demands for minorities are considered illegitimate and only the UK and Netherlands can be considered self-declared multicultural countries. It is these conceptions of citizenship as well as the general national opportunity structure which affect the repertoires of migrants (Koopmans 2005, 136). Therefore, among all their case studies, France, Netherlands and Britain are the countries that have attempted to make their immigrants into citizens.

However, while France has discouraged particular identities, Netherlands has been characterized by too much cultural pluralism, while Britain has managed to find the best balance between tolerance for cultural diversity and adaptation of immigrants. Consequently, effects on migrant homeland-oriented mobilization differ substantially between states. The exclusionary policies of Switzerland and Germany as well as the strong state sponsorship of particularist identities in the Netherlands has allowed for migrants in these states to reveal an increased identification with their home-country. By contrast, despite the 
differences between France and the UK, one observes the lowest levels of ethno-national identifications and homeland-oriented mobilizations among immigrants in these countries (Koopmans 2005, 144). This is because France's rejection of particularist identities, allow for mobilization around universalist identities.

In terms of the far-right, Koopmans et al. reject the often-made demand-side versus supply-side dichotomy as a path towards explanations for these parties. Instead, they opt to look for similar exogenous variables: on the one hand, those focusing on grievances and ethnic competition and on the other hand, opportunities and institutional frameworks. While grievances are direct responses to foreigners and migrants, opportunities theories emphasize the role of other political elites and institutions shaping the mobilization of extreme-right parties (Koopmans 2005, 182). Ultimately, they conclude that societal definitions of citizenship provide different sets of discursive opportunities that determine the degree of visibility and resonance of the extreme-right and its claims. The authors argue that it is the latter national configurations of citizenship alongside the party alignments of other parties which accounts for the presence of the radical right (Koopmans 2005, 202). In essence, their argument is one stressing the space which the radical right is allowed to occupy as a result of the positioning of the mainstream parties.

Therefore, depending on the configurations of citizenship and political institutions in each of the five states the radical right can become institutionalized, radicalized or marginalized. In Switzerland but most importantly in Germany, where the Christian Democratic Party already has a well established antiimmigration position - taking enough space on the right - and where citizenship configurations do not allow for much migrant integration, the radical right becomes radicalized. This is because it benefits from strong discursive opportunities but narrow political space.

In France, where there is a rejection of cultural groups and where mainstream parties accept republican universalist notions of citizenship, there is both the discursive opportunity as well as the political space for the radical right to denounce migrants as 'faux français'. This leads to an institutionalization of the radical right. In Britain, where there is both a lack of political space as well as weak discursive opportunities there is a marginalization of the party family. Finally in the Netherlands where there are weak discursive opportunities but ample political space, the authors argue that it is here where the radical right experiences populist mobilization (Koopmans 2005, 190).

Ultimately, national configurations of citizenship account for both the ability of the migrants to detach themselves from ethno-national identifications and homeland-oriented forms of mobilization as well as the ability of the far-right to emphasize the 'otherness' of the immigrant versus the native. Essentially, while many nuances of citizenship configurations may be able to achieve the former, it is only the British configuration of citizenship which is successful at squeezing the radical-right voice out of major political debates while also ensuring no migrant homeland-oriented mobilization. This is because, as previously mentioned, while the French notion of citizenship is based on the rejection of cultural group rights (a notion to which the radical-right can speak to as well), the British citizenship configuration allows for cultural differences (Koopmans 2005, 202). Ultimately, it is this latter aspect that delegitimizes the radical-right message aimed towards pointing towards the 'otherness' of the immigrant.

\section{Contrasting Conclusions}

In essence, through their different starting assumptions, all four works discussed arrive at substantially different conclusions about the radical right party family and migration. Mudde accepts an already existing public discontent. However, his party centric approach provides for an explanation which focuses on the party's ability to capture this discontent through a narrative containing nativism, authoritarianism and populism that presents the voter with a multi-dimensional enemy that is attacking his/her nation and state. The immigrant for Mudde represents only one such dimension alongside a plethora of other dimensions ranging from international organizations such as the EU to national mainstream political elites or cultural leaders. Immigrants are thus one of the causal factors yet by no means are they the sole variable responsible for the success of the radical right. Success lies within the party's very own ability to organize and produce an effective leadership which could seize votes. 
Like Mudde, both Williams and Givens reject the claim that radical right parties are solely dependent on rising immigration levels for their electoral and policy successes. Instead, they argue for intervening variables that mobilize anti-immigration sentiment. But how is this done? Williams and Givens offer separate explanations for why this occurs. Givens gives an institutionalist account, arguing that the ability to form coalitions and exploit factionalist divisions in legislative bodies accounts for the post-1980s successes of the radical right. Hence, most of the growth of right wing parties is removed from direct socioeconomic factors. As an explanation, this lacks emphasis on how parties and the discontent they exploit are formed in the first place, and fails to explore necessary variables for radical party genesis.

Williams generally accepts socioeconomic tensions as the starting point for radical right politics, but attributes the successes of radical right parties to their ability to link socioeconomic tensions to issue areas that they are prevalent in, such as immigration as opposed to economics or foreign policy. Williams' account is more focused on the social construction of ideas, which makes her a suitable companion for Mudde, and ultimately helps fill the hole in Givens' account regarding the relationship between radical parties and their voters that antecedes the relationship between radical parties and the legislative system. Though Williams' sociological perspective gives her a viewpoint that institutionalist approaches do not afford, it has its own weaknesses - explaining whether one society is more amenable to messages from the radical right than another is difficult, one can only identify whether a party has been successful at relating to voters once it has happened.

Finally, although having been published ahead of the other works, Koopmans et al. move completely away from the accepted causal relationship between migration and the radical right party family which the other works only partially challenge. Their conclusions lie perhaps in the different questions which they try to answer. They are not looking to identify independent variables that account for the dependent variable - the radical right. Such an approach would inevitably have to include a discussion of migration and ultimately taking a position on the causal relationship debate. Instead, their focus is on explaining both the integration of migrants as well as the radical right. Having identified national configuration of citizenship as an independent variable for the former, they test the same variable in the case of the radical right. Their approach leads them to a significantly different conclusion than the other works. They illustrate that configurations of citizenship are in fact responsible for both migrant mobilization and the political space available for the radical right.

However, although novel, their conclusions are not any less deterministic than the other three works. In essence, they argue that while France's universalism and Britain's tolerance prevent homelandoriented mobilization among migrants, the particularist identities sponsored by Germany and Switzerland as well as the universalist ones by France foster the presence of the radical right. Only the UK's right balance between inclusion and tolerance can prevent both. The model would subsequently imply that there is no clear relationship between immigration and radical-right parties but most importantly, that a British model is the only one available for securing migrant-inclusion and a marginalization of the party family. The problematic aspect of this is quite obvious as constitutional, societal as well as institutional factors would obviously prevent states from becoming 'like Britain' as Koopmans' conclusions seem to suggest.

\section{Conclusion}

Conclusively, Cas Mudde's Populist Radical Right Parties in Europe, Michelle Hale Williams' The Impact of Radical Right-Wing Parties in West European Democracies, Terri Givens' Voting Radical Right in Western Europe, and Ruud Koopmans' Contested Citizenship all attempt to dissect the apparently causal relationship between migration and the far-right movement and its political manifestation in Western Europe. In essence, While Mudde does not dispel this assumption; Givens brings in institutional factors as well. Williams, although not focusing so much on institutions, attempts to link the capitalization of radical right parties on the presence of immigrants with equally important economic factors such as unemployment. Finally, Ruud Koopmans argues that national configurations of citizenship account for both the ability of the migrants to detach themselves from ethno-national forms of 
mobilization as well as the ability of the far-right to engage in 'nativist' discourse successfully. Subsequently, for Mudde the relationship remains largely causal although not unicausal. For Williams, it is causal with institutions as intervening variables. For Givens, the relationship is complicated by the ability of the party to project its perception onto the voter in light of economic obstacles, while finally for Koopmans, the integration of immigrants as well as the voice of the radical right are both determined by institutional factors.

Finally, questions regarding immigration and the radical right still remain. Are the two linked or is the latter only marginally related to the former? If they are linked, does this say anything about the implication migration has for the future success of the party family? Are there institutional factors which can affect them or can particular forms of migrant mobilization along ethnic lines as well as far-right party internal dynamics circumvent some of these institutional constraints? Lastly, is it even possible or desirable to establish generalized inferences about the two as Mudde does with examples from both Eastern and Western Europe? Or is it more prudent to establish cross-national differences as illustrated by Koopmans? We do not hope to elaborate an answer for these questions, however, what we do hope to have achieved through our book review is a general synopsis of some of the debates which surround this particular aspect of both studies on immigration as well as studies on the radical right party family. Ultimately, we do believe that despite being marginal parities, the radical-right are not at the periphery of agenda-setting nor at the periphery of politics. In a world where globalization and modernity are not less important than the 1990s or early 2000s and where the movement of people is an ongoing reality, it is crucial to continue the effort of understanding both the party family itself as well as the phenomenon of migration with which it is so often associated.

\section{NOTES}

' The terms radical-right, far-right and new-right are often used inconsistently in scholarly literature. They all attempt at categorizing a post 1980s wave of parties that advocate economic deregulation but social conservatism and even xenophobia. In this review we will not pick one terminology over the others and we use these terms interchangeably to refer to the same party family.

\section{REFERENCES}

Givens, Terri. 2005. Voting Radical Right in Western Europe. New York: Cambridge University Press.

Koopmans, Ruud. 2005. Contested Citizenship: Immigration and Cultural Diversity in Europe. Minneapolis: University of Minnesota Press.

Mudde, Cas. 2007. Populist Radical Right Parties in Europe. New York: Cambridge.

Williams, Michelle Hale. 2006. The Impact of Radical Right-Wing Parties in West European Democracies. New York: Palgrave Macmillan. 